scores in sentencing him to death.

A 2002 Supreme Court ruling already bars the execution of people with an intellectual disability. But Hall's lawyers are expected to argue that many US states assess mental ability using outdated measures that take little or no account of current scientific research on the subject. Florida, in particular, is one of ten states in which anyone with an IQ score of above a certain number, usually 70 , is automatically considered to be intellectually competent and is therefore eligible for the death penalty. Psychologists contend that IQ tests are not precise enough to draw such a 'bright line'. Hall's IQ scores range from 60 to 80 , and many states would not consider him for the death penalty, say several specialists who have reviewed his case. Documents prepared for one of his trials quote clinicians saying that Hall "is mentally retarded, has always been mentally retarded, and will be mentally retarded for the remainder of his life".

There is a great deal resting on how the Supreme Court decides this case. According to one estimate, as many as $20 \%$ of the more than 3,100 people on death row in the United States may have some level of intellectual disability (R. Coyne and L. Entzeroth Geo. J. Fighting Pov. 3, 40; 1996). So a decision in Hall's favour could lead to hundreds of appeals, says Nancy Haydt, an attorney in Santa Barbara, California, who is compiling a database of pleas relating to intellectual disabilities in death-penalty cases.

But many mental-health specialists hope that the court will rule more broadly. In briefs filed in the case in December, professional organizations, including the American Psychological Association (APA) and the American Association on Intellectual and Developmental Disabilities (AAIDD), advocated for the court to set a new legal standard that reflects current research on intelligence. IQ tests were never designed to assess the criminal mind, psychologists argue. They say that the modern definition of intelligence - which includes the ability to learn and solve problems, relate to other people and function in society - is much more relevant.

\section{CRUEL AND UNUSUAL PUNISHMENT}

The confusion over the legal role of IQ began in 2002, when a Virginia man, Daryl Atkins, went before the Supreme Court to appeal his death sentence. Atkins and an accomplice had been arrested in 1996 for murdering a man. There were no witnesses, and Atkins's accomplice made a deal with prosecutors: in exchange for a life sentence, he testified that Atkins had held the gun. Atkins, who had an IQ of 59, smiled and doodled through his trial.

The Supreme Court ruled that it was "cruel and unusual" to execute a person who could not understand the consequences of his actions or the legal proceedings. It sent the case back to the Virginia court system, which changed Atkins's sentence to life imprisonment. The Supreme Court also ruled that death is not a suitable punishment for anyone who has been diagnosed as "mentally retarded" by standards such as those of the American Association on Mental Retardation (now the AAIDD). This organization's definition has three criteria: an IQ score two standard deviations below average (about 70); difficulty adapting and functioning in society; and evidence that the disability began before age 18 .

However, the court left it up to individual states to decide how to implement the Atkins

\section{"LOOKING AT}

\section{INTELLIGENCE AS A SINGLE NUMBER IS SUCH AN OUTMODED CONCEPT, WITH NO SCIENTIFIC VALIDITY."}

criteria. And the paths many have chosen have raised issues with all three (see 'Bright lines').

Looking at the IQ standard, for example, "the states took it as 'we can define intellectual disability however we want', says Harry Simon, an assistant federal defender in Sacramento, California. One result was Florida's bright line: an IQ score of above 70 would be enough to end a defendant's plea. Some states are even stricter: in Oklahoma, a single score above 75 from any test taken in a defendant's life automatically qualifies him or her for capital punishment.

Kent Scheidegger, legal director of the Criminal Justice Legal Foundation, a non-profit organization in Sacramento that supports the death penalty, says that the problem is the Atkins decision itself. "It created a rule of law that we have to crisply divide people in two categories - retarded and not retarded - and treat them differently," he says. "Because there isn't a clear line in reality, that is inherently problematic."

Each state now has to find some way to comply with that, Scheidegger says. The bright line rule, if nothing else, applies uniformly to all defendants, avoiding a situation whereby the outcome depends on which side has the better expert psychologist. The Florida Attorney General's office declined to comment for this article, citing the pending Supreme Court case, but its brief to the court argues that a ruling in Hall's favour would ensure that "states are constitutionally bound to vague, constantly evolving - and sometimes contradictory diagnostic criteria established by organizations committed to expanding Atkins's reach".

Yet psychologist Keith Widaman of the University of California, Davis, says that clinicians generally oppose a bright-line test, not least because IQ tests have an error margin of roughly ten points (see go.nature.com/ vmir87). Besides, most defendants have taken several IQ tests and achieved a range of scores, which can vary widely depending on the type of test and the version used. Widaman points out that one of the most commonly used IQ tests, the Wechsler Adult Intelligence Scale (WAIS), has only a few questions aimed at assessing people at the lower boundary of the normal intelligence range: right around 70 .

What is more, the tests themselves have evolved over time. Conventionally, they focused on 'crystallized' intelligence, which includes factors such as a person's knowledge and ability to comprehend, say, a text. But, especially during the past decade, Widaman says, test designers have been putting an increased emphasis on 'fluid' intelligence: how well an individual can absorb new information, make judgements and reason through a complex problem.

Interpreting test scores is complicated even further by a phenomenon known as the Flynn effect: the average IQ score on a given test rises by roughly three points per decade across a population. No one is sure why; proposed explanations range from better nutrition and prenatal care to increased standardized testing in schools.

Every ten years or so, psychologists must therefore renormalize IQ tests such as WAIS so that the population's average IQ remains at 100 . This means that a death-row prisoner such as Kevin Green, who in 1991 scored 71 on an IQ test last normalized in 1972, might have scored only 65 on a test normalized to the year he took it. After Green was convicted and sentenced to death in 2000, his lawyers appealed, arguing that the court should correct for the Flynn effect. Nevertheless, Green's score exceeded Virginia's bright line of 70 , and he was put to death in 2008 .

Whereas Hall v. Florida has focused on the standard error of measurement in IQ tests, some psychologists would like laws to reflect a broader understanding of intelligence. "Looking at it as a single number is such an outmoded concept, with no scientific validity," says Stephen Greenspan, a forensic psychologist in Littleton, Colorado, who consults on Atkins cases.

\section{NO LIMITS}

This is why the latest version of the Diagnostic and Statistical Manual of Mental Disorders (DSM-5), used by almost all US hospitals and health providers, deliberately avoided setting any IQ number as a limit for diagnosing intellectual disability, says James Harris, a psychiatrist at the Johns Hopkins University in Baltimore, Maryland, and the lead author of the DSM-5's chapter on the subject. IQ tests don't have much to say about a defendant's ability to function in society, he says. "They're not looking at what happens when someone says, 'I'm going to give you a reward if you go with me to rob the bank; it'll be a lot of fun and I'll even let you hold the gun."' But, he says, that kind of situation is likely to come up.

This is the realm of the second Atkins criterion, 'adaptive functioning', which is given equal weight to IQ scores by the DSM-5. It involves factors ranging from empathy and social skills to impulse control and judgement, says Harris 
- none of which bear much relation to standard IQ scores, particularly when brain damage is involved. Take the case of Michael Zack, who has been on death row in Florida since 1997 for murdering a woman he met at a bar. Over the course of several trials, his lawyers and a psychologist argued that Zack had brain damage caused by his mother's heavy drinking during pregnancy. Although fetal alcohol spectrum disorder does not necessarily lower standard IQ scores, it severely damages the midbrain, which is involved in the ability to learn from experience and to anticipate the consequences of one's actions. This could explain why Zack scored 79 on an IQ test yet was diagnosed as having the emotional maturity of a ten-year-old.

Psychologists assess adaptive behaviour using standardized tests that ask questions about real-life function, such as whether a person can tie their shoe-laces or write a cheque. These questionnaires are typically given to family members and close acquaintances rather than the individuals themselves, because people tend to exaggerate their own abilities.

But the tests are frequently misused in legal settings, says William Hennis, an attorney with Florida's Commission on Capital Cases in Fort Lauderdale. They are often given to prison guards, who say that the defendant is getting along perfectly well in maximum security. "In a situation where you get all your meals provided and are under surveillance and your entire life is organized to the minute, that's not an environment where you can do an adaptive functioning [assessment] that makes sense," Hennis says. To get a fair determination, he maintains, the test needs to be given to people who knew the defendant before he or she was in prison.

Some states have developed their own ways of measuring mental eligibility. Texas, which executes more prisoners than any other state, uses 'Briseño factors': a set of seven behavioural criteria formulated by the Texas Court of Criminal Appeals in 2004. The factors include whether family and acquaintances think that the defendant is mentally disabled, and his or her ability to answer direct questions, lie and plan ahead. The judges in the case wrote that they were following AAIDD guidelines, and described the seven factors as an attempt to be specific about "adaptive behaviour criteria [that] are exceedingly subjective". But the factors have become a lightning rod for critics. "They're criteria invented out of thin air by judges that have no validation in science," says Simon.

Such non-professional assessments can miss an important reality, he says: many disabled defendants hide behind a 'cloak of competence' by copying the actions of others or collecting books they are unable to read in order to appear literate. "A lot of people think they know what mental retardation looks like, but it doesn't look like anything," says Marc Tassé, a psychologist at Ohio State University in Columbus. Later this year, the AAIDD will release the first adaptive-behaviour test specifically designed to diagnose mild intellectual disability in young people, called the Diagnostic Adaptive Behavior Scale (DABS). "These death-penalty cases made us realize the importance of designing a test around the cut-off," says Tassé, who is heading the project.

\section{BRIGHT LINES}

Every US state must decide for itself whether a convicted criminal is too intellectually disabled to receive the death penalty. Many states - often those with many prisoners on death row* — do this by drawing a 'bright line', whereby anyone with an IQ of above, say, 70 is automatically eligible for execution. In the process, some states ignore the uncertainties and limitations of IQ tests.

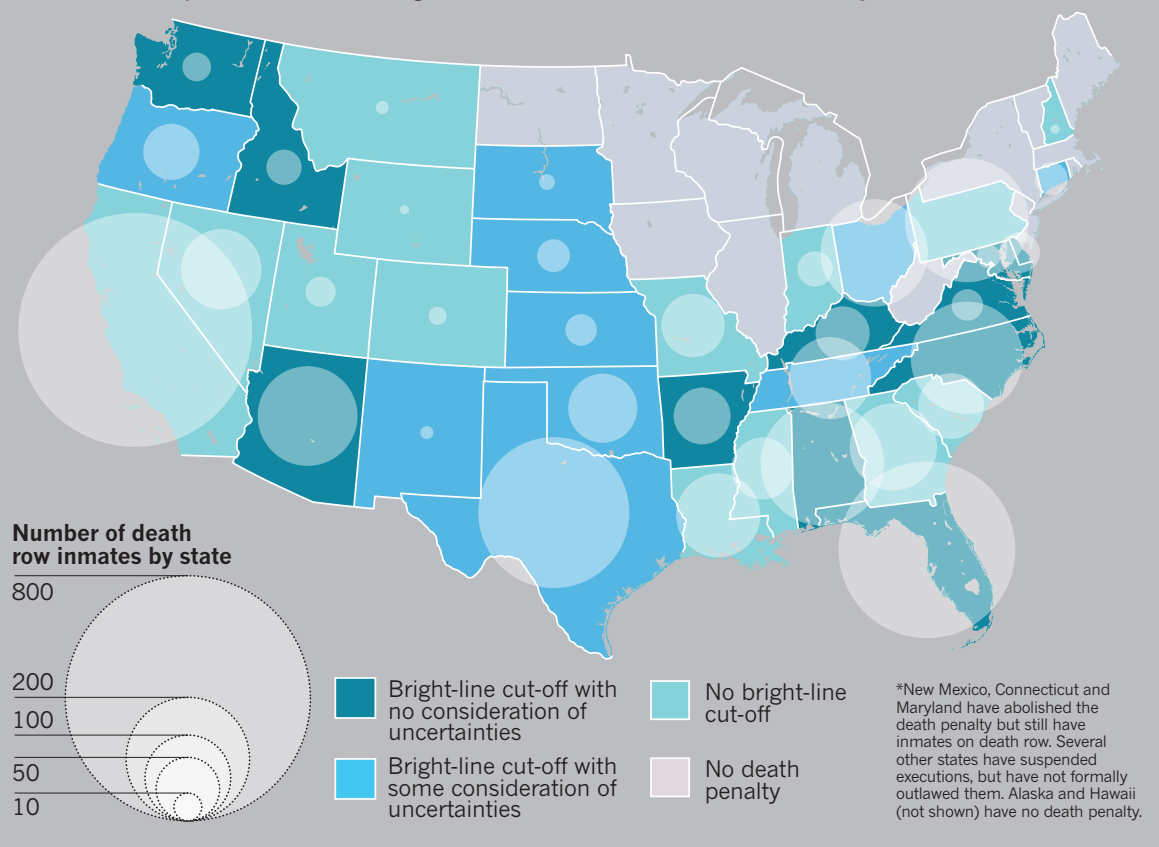

One of DABS's novel contributions will be questions about gullibility, which is a hallmark of intellectual disability. Criminals with an intellectual disability often have an accomplice, who might have led them into the crime, says Tassé.

\section{ENVIRONMENTAL DAMAGE}

Often, the most difficult of the Atkins criteria for defence lawyers to prove is the third: has a defendant been intellectually disabled since before the age of 18 ? Clues can sometimes be found by looking at a defendant's early environment. Childhood neglect and abuse, for instance, can lower IQ substantially. Court documents such as Hall's brim with tales of abuse by parents and others, damaging the children's brains with blows to the head and creating traumatic memories. But records are often fragmentary or missing, forcing defence lawyers to rely on families' and teachers' subjective memories. Hennis once tried to find childhood records on a client, Dean Kilgore, who had grown up as the son of poor black sharecroppers in 1950s Mississippi. Only after days of searching did Hennis turn up 50-year-old juvenile-conviction records revealing that Kilgore had been described as "brain damaged" by others at his work camp.

Psychologists hoping for better courtroom science are encouraged by the Supreme Court's decision to hear Hall v. Florida. Conceivably, the court could rule that states should abide by the DSM-5's diagnostic criteria, although Greenspan admits that such a broad ruling is unlikely. It is more probable that the court will decide that states must account for standard errors in IQ scores, or emphasize diagnoses by clinical psychologists.

Florida contends that its method for assessing intellectual abilities meets the standards set out in Atkins and that a ruling in Hall's favour would unleash an unwarranted flood of appeals. As the state Attorney General's office wrote in its brief to the Supreme Court, "future litigation would be endless".

But advocates for some death-row prisoners are confident. "The smart better's money is that it looks good for Hall," says Lee Kovarsky, an attorney at the University of Maryland in Baltimore, who represented Marvin Wilson, a convicted killer with an IQ of 61 who was executed in Texas in 2012. In recent cases involving science, the Supreme Court has been very open to expert opinions - and there are plenty to choose from here. Among them are the briefs filed by the AAIDD and APA. Even a group of dozens of former judges and law-enforcement officials filed a brief in Hall's favour, encouraging the court to account for standard error of measurement in IQ assessments. "I think it's a very powerful statement about the dilemma that we're in," Harris says of the briefs. "We cannot reduce the life of a human being to a single number."

Sara Reardon is a reporter for Nature in Washington DC. 